\title{
Awakenings: From empiricism to an evidence-based management of malignant pleural effusions
}

\author{
Gaetano Rocco, MD, FRCSEd
}

\footnotetext{
From the Division of Thoracic Surgery, Thoracic Department, Istituto Nazionale Tumori, IRCCS, Pascale Foundation, Naples, Italy.

Disclosures: Author has nothing to disclose with regard to commercial support.

Received for publication May 7, 2018; revisions received May 8, 2018; accepted for publication May 9, 2018; available ahead of print July 13, 2018.

Address for reprints: Gaetano Rocco, MD, FRCSEd, Via Terminio 1, Serino (Avellino) 83028, Italy (E-mail: gaetanorocco60@gmail.com).

J Thorac Cardiovasc Surg 2018;156:1260-1

$0022-5223 / \$ 36.00$

Copyright (c) 2018 by The American Association for Thoracic Surgery

https://doi.org/10.1016/j.jtcvs.2018.05.097
}

The contribution in this issue of the Journal provided by Demmy ${ }^{1}$ is particularly interesting because it suggests, among others, at least 3 considerations relevant to the current management of malignant pleural effusions that may foster new ideas. First, Demmy ${ }^{1}$ emphasizes the results of the CALGB (Cancer and Leukemia Group B) 9334 trial, demonstrating a substantial equipoise between talc slurry and video-assisted thoracoscopic surgery (VATS) in effecting pleurodesis as well as an increased incidence of pneumonia in the thoracoscopic arm. ${ }^{1}$ Second, CALGB 30102, which compared a tunneled intrathoracic catheter (PleurX; Becton, Dickinson and Company, Franklin Lakes, NJ) with talc slurry, failed to recruit because the PleurX catheter had the perceived advantage of allowing early discharge and sometimes no hospitalization. ${ }^{1}$ Third, the AMPLE (Australasian Malignant Pleural Effusion) trial comparing a tunneled intrathoracic catheter with pleurodesis demonstrated a 2-day reduction in length of stay relative to surgical pleurodesis. ${ }^{1}$ These 3 arguments point at the possibility that the recently investigated awake, nonintubated uniportal VATS pleurodesis ${ }^{2-4}$ may effectively reduce the incidence of pneumonia by avoiding general anesthesia and intubation and, compared with traditional multiport VATS, minimize the need for hospitalization of patients with malignant effusions. ${ }^{3,4}$ Referring physicians and patients should be made aware of the current perspectives of anesthetic management, which may contemplate the triad of awake (ie, no level of sedation, full consciousness), locoregional anesthesia, and no intubation. Awake and uniportal VATS pleurodesis may be offered to a heterogeneous variety of patients, irrespective of extremes of age, body mass index, and comorbidities. $^{3}$ In this setting, awake uniportal VATS maybe an ideal combination to reduce further the length of stay after surgical pleurodesis, reported to be around 4 postoperative days in a series of 339 patients managed with uniportal VATS pleurodesis predominantly performed with patient's under general anesthesia. ${ }^{4}$ In this setting, a

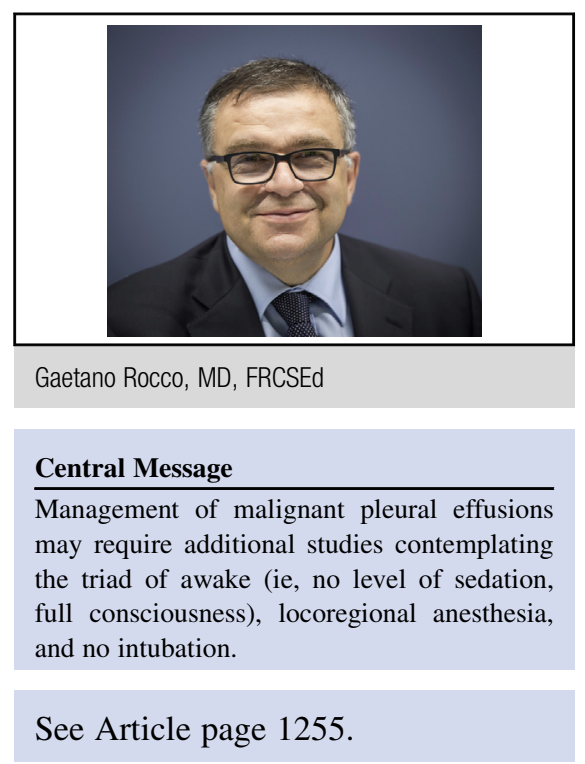

prospective, randomized trial comparing awake (uniportal) VATS and PleurX could provide the thoracic surgical community with a much-awaited option to solve a clinical issue often addressed with an empirical approach.

In addition, Demmy ${ }^{1}$ has another important merit when he tries to emphasize the need to find the science behind the routine practice of draining malignant pleural effusions. An interesting observation is the focus on the measurement of pleural elastance (ie, pleural manometry ${ }^{5}$ ) to predict accurately and therefore prevent the dreaded "trapped lung" stage. Furthermore, despite the recent evidence emerging from a recently published multicentric UK-based trial demonstrating that talc administered through an indwelling catheter is twice as effective in inducing pleurodesis as an indwelling catheter alone, ${ }^{6}$ Demmy ${ }^{1}$ elaborates on the need for an alternative agent to be distributed in the pleural space that meets improved chemicophysical criteria relative to talc. ${ }^{1}$ In fact, the potential interference of talc with the metabolism in the pleura and lymph nodes of the often sarcopenic patients with malignant pleural effusions may be of some oncologic relevance and should be more thoroughly investigated. ${ }^{1}$ In addition, a careful assessment of postpleurodesis quality of life is mandatory, given the low impact of these procedures on these patients' survival. In this setting, Demmy ${ }^{1}$ focuses his attention on 2 recently devised trials (AMPLE2 and OPTIMUM [Out Patient Talc Slurry via Indwelling Pleural Catheter for Malignant Pleural Effusion 
vs Usual Inpatient Management]) that are currently looking at defining the quality of life of patients who are in fragile condition and desire to see their problem resolved once and for all with minimal, if any, hospitalization and domiciliary care. Once again, this argument seems to pave the way to contemplate a clinical trial of awake and nonintubated (uniportal) VATS talc pleurodesis versus PleurX talc pleurodesis to answer the unresolved questions still pending when the management of these often-challenging patients is considered.

\section{References}

1. Demmy TL. Optimizing the study of tunneled intrapleural catheters for malignant pleural effusions. J Thorac Cardiovasc Surg. 2018;156:1255-9.
2. Pompeo E, Dauri M. Awake Thoracic Surgery Research Group. Is there any benefit in using awake anesthesia with thoracic epidural in thoracoscopic talc pleurodesis? J Thorac Cardiovasc Surg. 2013;146:495-7.e1.

3. Katlic MR. Five hundred seventy-six cases of video-assisted thoracic surgery using local anesthesia and sedation: lessons learned. J Am Coll Surg. 2018;226: 58-63.

4. Rocco G, Martucci N, La Manna C, Jones DR, De Luca G, La Rocca A, et al Ten-year experience on 644 patients undergoing single-port (uniportal) videoassisted thoracoscopic surgery. Ann Thorac Surg. 2013;96:434-8.

5. Grabczak EM, Krenke R, Zielinska-Krawczyk M, Light RW. Pleural manometry in patients with pleural diseases - the usefulness in clinical practice. Respir Med. January 31, 2018 [Epub ahead of print].

6. Bhatnagar R, Keenan EK, Morley AJ, Kahan BC, Stanton AE, Haris M, et al Outpatient talc administration by indwelling pleural catheter for malignant effusion. N Engl J Med. 2018;378:1313-22.

7. McDonald CM, Pierre C, de Perrot M, Darling G, Cypel M, Pierre A, et al. Efficacy and cost of awake thoracoscopy and video-assisted thoracoscopic surgery in the undiagnosed pleural effusion. Ann Thorac Surg. March 22, 2018 [Epub ahead of print]. 